\title{
Potential impact of 2018 Korean Society of Hypertension guidelines on Korean population: a population-based cohort study
}

Ju-Seung Kwun ${ }^{1,2}$, Sun-Hwa Kim ${ }^{1}$, Si-Hyuck Kang ${ }^{1,2^{*}}$ (D), Chang-Hwan Yoon ${ }^{1,2}$, Hae-Young Lee ${ }^{2,3}$, Kwang-II Kim², Tae-Jin Youn ${ }^{1,2}$, In-Ho Chae ${ }^{1,2}$ and Cheol-Ho Kim²

\begin{abstract}
Background: The Korean Society of Hypertension (KSH) revised the local guidelines for hypertension in 2018. The present study sought to evaluate the potential impact of the $2018 \mathrm{KSH}$ guidelines on hypertension management status among the Korean population in terms of prevalence of hypertension, antihypertensive medical treatment recommendations, and control status in Korean adults.

Methods: We used data from the Korea National Health and Nutrition Examination Survey to estimate the number and percentage of Korean adults who have hypertension according to blood pressure (BP) classification, are recommended to receive antihypertensive medical treatment, and are receiving medical treatment and have BP in the optimal range according to the new recommendations. Adults aged 30 years or older who participated in the survey between 2013 and 2015 were selected for this study.

Results: The prevalence of hypertension was 30.5\% among Korean adults aged 30 years or older. The percentage of subjects who are recommended to be treated with antihypertensive medications substantially increased from 32.5 to $37.8 \%$, which translates to 1.6 million adults. Among the hypertensive patients who were receiving medical treatment, 38.6\% were shown to have adequate BP levels as recommended by the $2018 \mathrm{KSH}$ guidelines compared with 51.8\% according to the previous 2013 guidelines.

Conclusions: The present study reports the potential impact of the $2018 \mathrm{KSH}$ guidelines on the prevalence of hypertension, antihypertensive medical treatment recommendations, and control status for Korean adults. The 2018 $\mathrm{KSH}$ guidelines recommend more intensive BP control compared with previous guidelines. This study suggests that there is large scope for improvement in hypertension management in the Korean population.
\end{abstract}

Keywords: Hypertension, Blood pressure, Korea National Health and nutrition examination survey (KNHANES), 2017 ACC/AHA guidelines, 2018 KSH guidelines

\footnotetext{
* Correspondence: eandp303@snu.ac.kr

${ }^{1}$ Cardiovascular Center, Department of Internal Medicine, Seoul National

University Bundang Hospital, 82, Gumi-Ro 173 Beon-Gil, Bundang-Gu,

Seongnam-Si, Gyeonggi-Do 13620, South Korea

${ }^{2}$ Department of Internal Medicine, Seoul National University, Seoul, South

Korea

Full list of author information is available at the end of the article
}

C The Author(s). 2020 Open Access This article is distributed under the terms of the Creative Commons Attribution 4.0 International License (http://creativecommons.org/licenses/by/4.0/), which permits unrestricted use, distribution, and reproduction in any medium, provided you give appropriate credit to the original author(s) and the source, provide a link to the Creative Commons license, and indicate if changes were made. The Creative Commons Public Domain Dedication waiver (http://creativecommons.org/publicdomain/zero/1.0/) applies to the data made available in this article, unless otherwise stated. 


\section{Background}

Elevated blood pressure (BP) is a leading global health risk factor $[1,2]$. Elevated BP increases the risk of cardiovascular and renal events in a linear manner, and evidence indicates that the linear relationship extends down to $115 / 75$ $\mathrm{mmHg}$ [3]. Recent studies have shown the benefits of intensive systolic BP control $<130 \mathrm{mmHg}$ in terms of adverse cardiovascular events and mortality [4].

The 2017 American College of Cardiology/American Heart Association (ACC/AHA) guidelines for hypertension lowered the hypertension criteria, BP threshold for medical treatment, and treatment goals [5]. A populationbased study from the United States estimated that the prevalence of hypertension increased substantially, but the increase in the number of adults recommended to take antihypertensive medication was relatively small [6]. It was also shown that more intensive BP lowering would be required for many adults taking antihypertensive medication. A previous study showed that there should be a similar impact if the 2017 ACC/AHA guidelines were directly applied to the Korean population [7].

Recently, the Korean Society of Hypertension (KSH) updated the local guidelines for hypertension [8-10]. The criterion for hypertension was maintained as systolic BP $\geq 140 \mathrm{mmHg}$ or diastolic BP $\geq 90 \mathrm{mmHg}$ [8]. However, the new guidelines also support intensive BP control consistent with the 2017 ACC/AHA guidelines. Treatment threshold and BP target have been lowered for a variety of subgroups [9].

The present study was designed to estimate the potential impact of the 2018 guidelines for hypertension on the Korean population in terms of prevalence of hypertension, antihypertensive medical treatment recommendations, and control status in Korean adults. We aimed to report the number and percentage of Korean adults who have hypertension according to the BP classification, are recommended to receive antihypertensive medical treatment, and are receiving medical treatment and have BP in the optimal range according to the new recommendations.

\section{Methods}

\section{Aim}

The present study sought to evaluate the potential impact of the $2018 \mathrm{KSH}$ guidelines on hypertension management status among the Korean population in terms of prevalence of hypertension, antihypertensive medical treatment recommendations, and control status for Korean adults.

\section{Data source and study population}

Data from the Korea National Health and Nutrition Examination Survey (KNHANES) were used for the study purpose. KNHANES is a nationally representative surveillance system that assesses the health and nutritional status of Koreans [11]. The surveys are conducted by the Korea Centers for Disease Control and Prevention. Approximately 10,000 individuals are included each year, and data on socioeconomic status, health-related behaviors, quality of life, healthcare utilization, anthropometric measures, biochemical and clinical profiles for non-communicable diseases and dietary intakes with three component surveys are collected [11]. In the present study, adults aged 30 years or older were chosen among the participants in the KNHANES between 2013 and 2015.

\section{BP measurement}

BP was measured by four nurses who underwent specialized training and whose performance was regularly monitored and certified. A mercury sphygmomanometer (Baumanometer; WA Baum Co., New York, NY, USA) was used for BP measurements. Study subjects were recommended to rest in a seated position for at least $5 \mathrm{~min}$. BP was measured three times on the subjects' right arms using an appropriately sized arm cuff. The average of the second and third measurements was used for data analysis.

\section{Definition}

Table 1 summarizes the similarities and differences in BP classification between the 2018 and 2013 guidelines. The 2018 KSH guidelines recommended pharmacological treatment for $\mathrm{BP} \geq 130 / 80 \mathrm{mmHg}$ if a subject has three or more cardiovascular risk factors or subclinical organ damage. More strict BP control was recommended compared to the previous version for subjects with cardiovascular diseases or diabetes and adults aged more than 65 years. BP was classified as normal, elevated, and hypertension (grades 1 and 2) according to the $2018 \mathrm{KSH}$ hypertension guidelines. Hypertension was defined as systolic BP $\geq 140$ $\mathrm{mmHg}$ or diastolic BP $\geq 90 \mathrm{mmHg}$, and those already taking antihypertensive medications were also regarded as having hypertension. The number and percentage of adults requiring antihypertensive drug treatment were presented according to the guidelines. Control rate was defined as the proportion of adults for whom the recommended BP goals were achieved among those who were receiving hypertension treatment.

\section{Statistical analysis}

Data are presented as mean \pm standard error or \% (standard error). Weights based on the complex sampling design of KNHANES were used for all the statistical analyses to avoid biased estimates [11]. The variables representing strata, cluster, and weight were included in the raw data. The number and proportion of BP classification, subjects recommended for medical treatment, and those under control were estimated by weighted means. Statistical analyses were conducted using $\mathrm{R}$ programming version 3.2.4 
Table 1 Brief comparison of the 2018 Korean Hypertension guidelines and 2013 Korean Hypertension guidelines

\begin{tabular}{|c|c|c|}
\hline & 2018 Korean Hypertension guidelines & 2013 Korean Hypertension guidelines \\
\hline Definition of hypertension & $\mathrm{SBP} \geq 140 \mathrm{mmHg}$ or $\mathrm{DBP} \geq 90 \mathrm{mmHg}$ & $\mathrm{SBP} \geq 140 \mathrm{mmHg}$ or $\mathrm{DBP} \geq 90 \mathrm{mmHg}$ \\
\hline $\begin{array}{l}\text { Recommended } \\
\text { pharmacologic treatment }\end{array}$ & $\begin{array}{l}\text { - General population: } \mathrm{SBP} \geq 140 \mathrm{mmHg} \text { or } \mathrm{DBP} \geq 90 \mathrm{mmHg} \\
\text { - DM, CKD, CVD: } \mathrm{SBP} \geq 130 \mathrm{mmHg} \text { or } \mathrm{DBP} \geq 80 \mathrm{mmHg} \\
\text { - Presence } \geq 3 \text { of } \mathrm{CVD} \text { risk factors or subclinical organ damage: } \\
\mathrm{SBP} \geq 130 \mathrm{mmHg} \text { or } \mathrm{DBP} \geq 80 \mathrm{mmHg}\end{array}$ & $\begin{array}{l}\text { - General population: } \mathrm{SBP} \geq 140 \mathrm{mmHg} \text { and } \mathrm{DBP} \geq 90 \\
\mathrm{mmHg} \\
\text { - DM, CKD, CVD: SBP } \geq 130 \mathrm{mmHg} \text { or } \mathrm{DBP} \geq 80 \mathrm{mmHg}\end{array}$ \\
\hline Target BP goal & $\begin{array}{l}\text { - General population: SBP }<140 \mathrm{mmHg} \text { and } \mathrm{DBP}<90 \mathrm{mmHg} \\
\text { - DM without CVD: SBP }<140 \mathrm{mmHg} \text { and } \mathrm{DBP}<85 \mathrm{mmHg} \\
\text { - DM with CVD: SBP }<130 \mathrm{mmHg} \text { and DBP }<80 \mathrm{mmHg} \\
\text { - Stroke: } \mathrm{SBP}<140 \mathrm{mmHg} \text { and } \mathrm{DBP}<90 \mathrm{mmHg} \\
\text { - Presence } \geq 3 \text { risk factors: } \mathrm{SBP}<130 \mathrm{mmHg} \text { and } \mathrm{DBP}<80 \\
\mathrm{mmHg} \\
\text { - CVD: } \mathrm{SBP}<130 \mathrm{mmHg} \text { and } \mathrm{DBP}<80 \mathrm{mmHg} \\
\text { - CKD without albuminuria: } \mathrm{SBP}<140 \mathrm{mmHg} \text { and } \mathrm{DBP}<90 \\
\mathrm{mmHg} \\
\text { - CKD with albuminuria: SBP }<130 \mathrm{mmHg} \text { and } \mathrm{DBP}<80 \mathrm{mmHg} \\
\text { - Elderly ( } \geq 65 \text { years of age without DM or CKD): SBP }<140 \\
\mathrm{mmHg} \text { and DBP }<90 \mathrm{mmHg}\end{array}$ & $\begin{array}{l}\text { - General population: } \mathrm{SBP}<140 \mathrm{mmHg} \text { and } \mathrm{DBP}<90 \\
\text { mmHg } \\
\text { - DM: SBP }<140 \mathrm{mmHg} \text { and } \mathrm{DBP}<85 \mathrm{mmHg} \\
\text { - Stroke: } \mathrm{SBP}<140 \mathrm{mmHg} \text { and } \mathrm{DBP}<90 \mathrm{mmHg} \\
\text { - CAD: SBP }<140 \mathrm{mmHg} \text { and } \mathrm{DBP}<90 \mathrm{mmHg} \\
\text { - CKD without albuminuria: } \mathrm{SBP}<140 \mathrm{mmHg} \text { and DBP } \\
<90 \mathrm{mmHg} \\
\text { - CKD with albuminuria: SBP }<130 \mathrm{mmHg} \text { and DBP }< \\
80 \mathrm{mmHg} \\
\text { - Elderly ( } \geq 65 \text { years of age without DM or CKD): SBP }< \\
150 \mathrm{mmHg} \text { and DBP }<90 \mathrm{mmHg}\end{array}$ \\
\hline
\end{tabular}

$S B P$ systolic blood pressure, $D B P$ diastolic blood pressure, $D M$ diabetes mellitus; $C K D$ chronic kidney disease, $C V D$ cardiovascular disease, $C A D$ coronary artery disease

(http://www.R-project.org; The R Foundation for Statistical Computing, Vienna, Austria).

\section{Results}

\section{Prevalence of hypertension}

A total of 9.1 million Korean adults (30.5\%) were estimated to have hypertension (Fig. 1a). Approximately two-thirds were already receiving medical treatment, and the remaining one third were not. The prevalence of hypertension was higher among older adults, men and those living in rural areas (Additional file 1). Prehypertension accounted for 5.6 million adults (18.8\%), whereas 1.7 million (5.5\%) who had been regarded as having prehypertension according to the 2013 guidelines were classified as having elevated BP according to the new guideline.
The characteristics of the subjects in each BP category are described in Table 2. Compared to adults with hypertension, those with prehypertension were relatively younger and had lower prevalence of obesity and comorbidities. The estimated 10-year cardiovascular risk of normal BP groups was lower than hypertension groups. In contrast, adults with elevated BP were older than normal BP, grade 1 or grade 2 hypertension groups and their estimated cardiovascular risk was comparable to grade 1 hypertension.

\section{Potential impact on pharmacological antihypertensive treatment}

As shown in Table 1, the $2018 \mathrm{KSH}$ guidelines expanded the indication for the pharmacologic treatment to prehypertensive

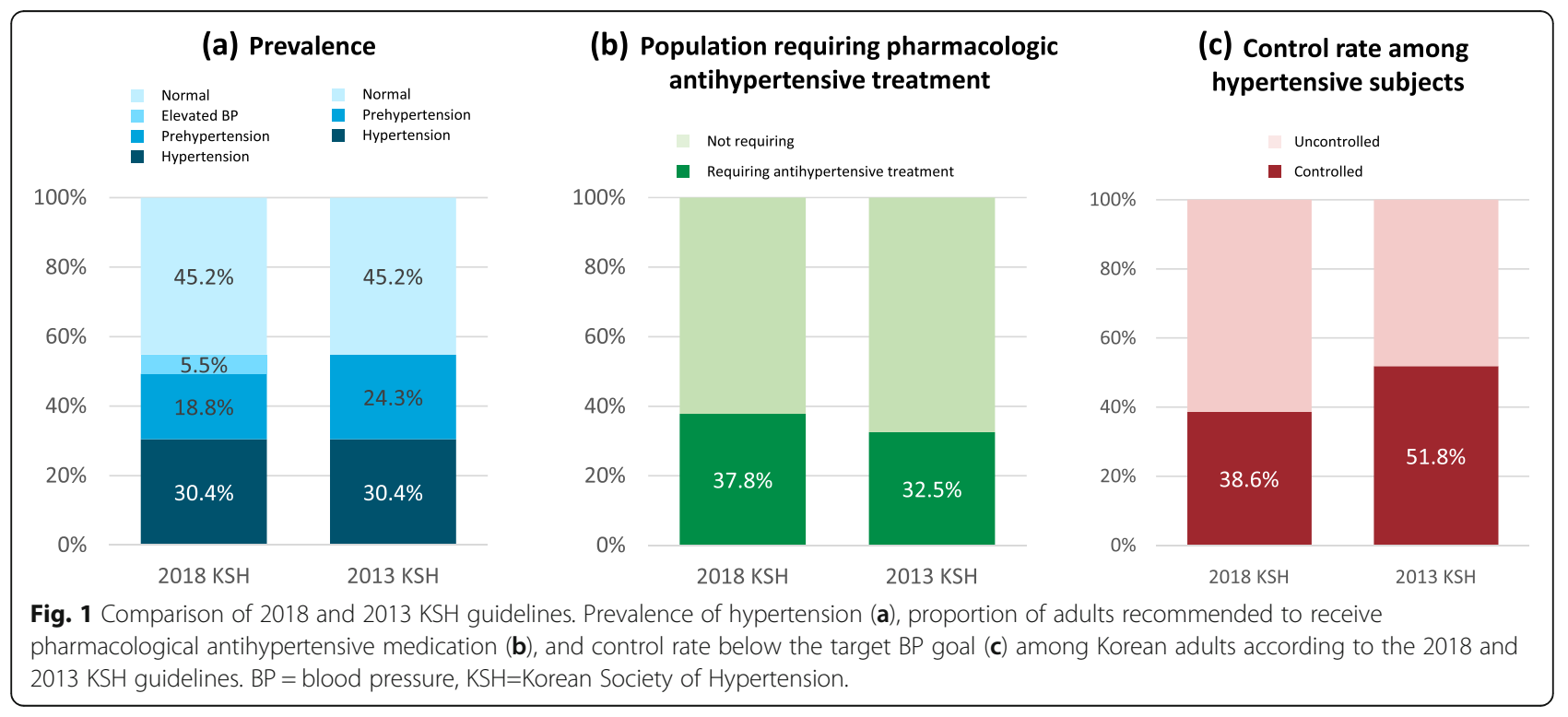


Table 2 Subject characteristics according to blood pressure (BP) category and the use of antihypertensive medications

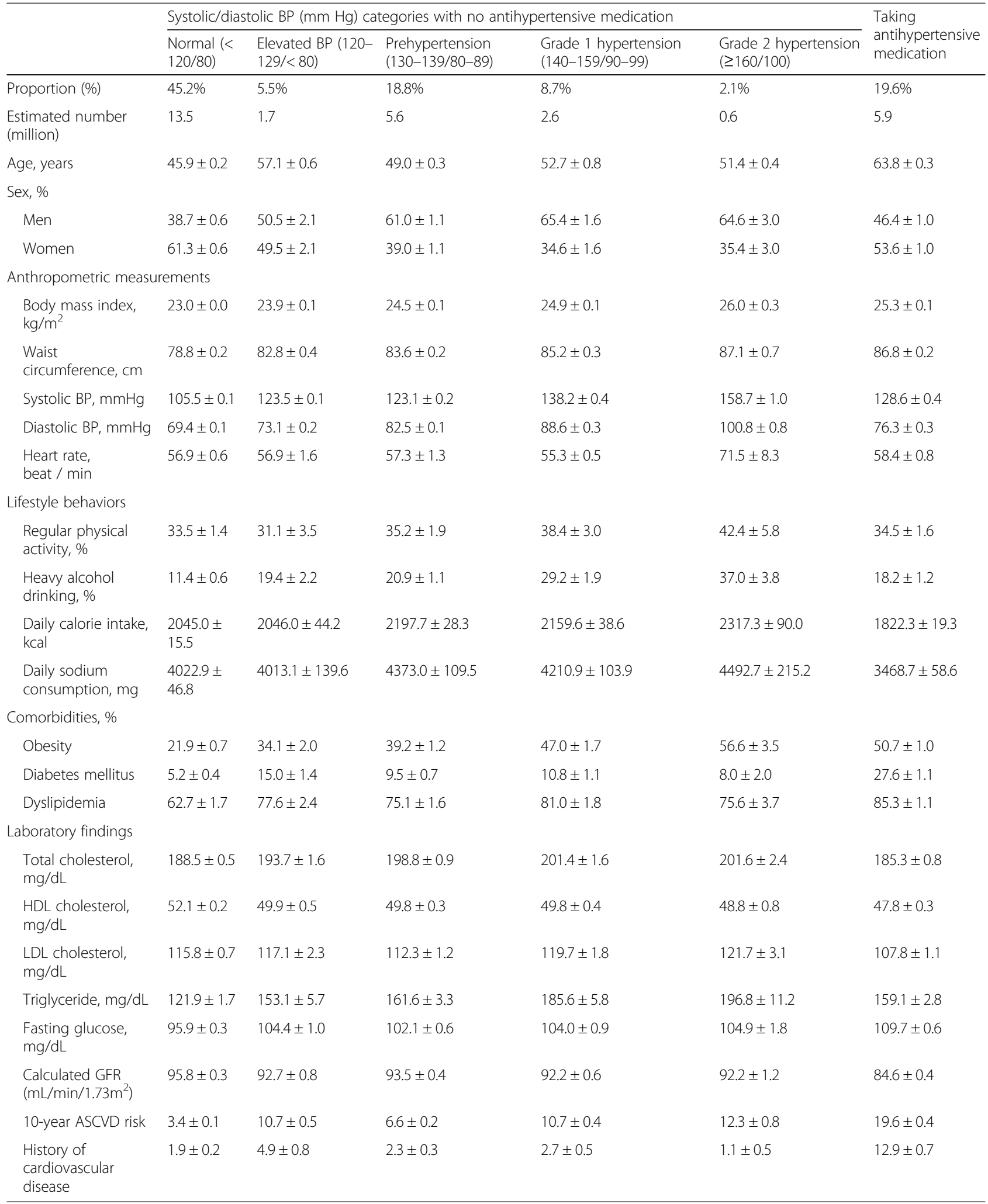


subjects who are at high risk. The percentage of subjects who were recommended antihypertensive medical treatment increased from 32.5 to $37.8 \%$ (Fig. 1b), which is translated into 1.6 million adults (Table 3). The increase was numerically greater for men and middle-aged adults: three fourths of the increase were among men, and those between 40 and 69 years. Accordingly, the treatment rate among those indicated for medical treatment decreased from 60.4 to $52.0 \%$.

\section{Potential impact on control rate}

In the $2018 \mathrm{KSH}$ guidelines, a strict BP target is recommended for several clinical situations such as the presence of cardiovascular disease and multiple risk factors. Among the adults who were receiving medical treatment, $38.6 \%$ were shown to have adequate BP levels recommended by the $2018 \mathrm{KSH}$ guidelines compared with $51.8 \%$ according to the 2013 guidelines (Fig. 1c) (Table 4). The control rate was numerically low among men and younger people. Additional file 2 presents the difference in control rate according to specific conditions, which shows that tighter $\mathrm{BP}$ control is required especially among those with cardiovascular disease, stroke, and advanced age.

\section{Discussion}

The present study estimated the potential impact of the 2018 KSH guidelines on the prevalence of hypertension, antihypertensive medical treatment recommendation, and control status in Korean adults. The guidelines maintained the definition criteria for hypertension, and thus, the prevalence of hypertension in Korea remained at $30.5 \%$. However, as more intensive BP control is recommended in the new guideline, there was a significant increase in the number of adults requiring antihypertensive medication. The proportion increased from 32.5 to $37.8 \%$, which was responsible for 1.6 million Koreans. The rate of hypertensive patients whose BP was below recommended levels also decreased.

The 2018 KSH guidelines maintained its BP criteria for hypertension (systolic BP $\geq 140 \mathrm{mmHg}$ or diastolic BP $\geq 90 \mathrm{mmHg}$ ) [8]. There were only small changes in the ranges of elevated $\mathrm{BP}$ and prehypertension [12]. The

Table 3 Percentage and number of Korean adults recommended antihypertensive medical treatment

\begin{tabular}{|c|c|c|c|c|c|c|}
\hline & \multicolumn{3}{|l|}{ Percentage } & \multicolumn{3}{|l|}{ Number } \\
\hline & 2018 KSH guidelines & 2013 KSH guidelines & Difference & 2018 KSH guidelines & 2013 KSH guidelines & Difference \\
\hline Total & $37.8 \pm 0.6$ & $32.5 \pm 0.6$ & $5.3 \pm 0.2$ & 11.3 & 9.7 & 1.6 \\
\hline \multicolumn{7}{|l|}{ Sex } \\
\hline Male & $45.1 \pm 0.8$ & $36.6 \pm 0.8$ & $8.5 \pm 0.5$ & 6.4 & 5.2 & 1.2 \\
\hline Female & $31.1 \pm 0.7$ & $28.7 \pm 0.7$ & $2.3 \pm 0.2$ & 4.8 & 4.5 & 0.4 \\
\hline \multicolumn{7}{|l|}{ Age (years) } \\
\hline $30-39$ & $12.8 \pm 0.8$ & $9.5 \pm 0.7$ & $3.3 \pm 0.4$ & 0.9 & 0.7 & 0.2 \\
\hline $40-49$ & $27.2 \pm 0.9$ & $21.5 \pm 0.9$ & $5.7 \pm 0.5$ & 2.1 & 1.6 & 0.4 \\
\hline $50-59$ & $45.2 \pm 1.1$ & $36.4 \pm 1.1$ & $8.8 \pm 0.6$ & 3.3 & 2.6 & 0.6 \\
\hline $60-69$ & $57.9 \pm 1.2$ & $52.9 \pm 1.2$ & $5.1 \pm 0.5$ & 2.5 & 2.3 & 0.2 \\
\hline $70+$ & $68.2 \pm 1.2$ & $66.3 \pm 1.2$ & $1.8 \pm 0.3$ & 2.6 & 2.5 & 0.1 \\
\hline \multicolumn{7}{|l|}{ Area of residence } \\
\hline Urban area & $36.7 \pm 0.7$ & $31.6 \pm 0.6$ & $5.1 \pm 0.3$ & 8.9 & 7.7 & 1.2 \\
\hline Rural area & $42.7 \pm 1.4$ & $36.5 \pm 1.4$ & $6.2 \pm 0.5$ & 2.4 & 2.0 & 0.3 \\
\hline \multicolumn{7}{|l|}{ Income quartiles } \\
\hline Highest & $35.7 \pm 1.1$ & $30.5 \pm 1.0$ & $5.3 \pm 0.5$ & 2.7 & 2.3 & 0.4 \\
\hline Upper middle & $36.3 \pm 1.0$ & $31.3 \pm 1.0$ & $5.0 \pm 0.4$ & 2.7 & 2.3 & 0.4 \\
\hline Lower middle & $39.5 \pm 1.1$ & $33.4 \pm 1.0$ & $6.2 \pm 0.5$ & 3.0 & 2.5 & 0.5 \\
\hline Lowest & $39.6 \pm 1.0$ & $35.0 \pm 1.0$ & $4.6 \pm 0.5$ & 2.9 & 2.5 & 0.3 \\
\hline \multicolumn{7}{|l|}{ Education levels } \\
\hline Primary & $62.1 \pm 1.0$ & $57.3 \pm 1.1$ & $4.8 \pm 0.5$ & 3.8 & 3.5 & 0.3 \\
\hline Middle & $47.8 \pm 1.5$ & $41.7 \pm 1.4$ & $6.2 \pm 0.7$ & 1.5 & 1.3 & 0.2 \\
\hline High & $32.7 \pm 0.9$ & $27.3 \pm 0.8$ & $5.4 \pm 0.4$ & 3.2 & 2.7 & 0.5 \\
\hline University/college & $24.5 \pm 0.8$ & $19.2 \pm 0.8$ & $5.3 \pm 0.4$ & 2.5 & 2.0 & 0.5 \\
\hline
\end{tabular}


Table 4 Proportion and number of subjects with hypertension whose blood pressure is controlled under recommended levels

\begin{tabular}{|c|c|c|c|c|c|c|}
\hline & \multicolumn{3}{|l|}{ Proportion } & \multicolumn{3}{|l|}{ Number } \\
\hline & 2018 KSH guidelines & 2013 KSH guidelines & Difference & 2018 KSH guidelines & 2013 KSH guidelines & Difference \\
\hline Total & $38.6 \pm 1.0$ & $51.8 \pm 1.1$ & $13.2 \pm 0.6$ & 2.8 & 3.7 & 1.0 \\
\hline \multicolumn{7}{|l|}{ Sex } \\
\hline Male & $32.1 \pm 1.3$ & $45.1 \pm 1.5$ & $13.0 \pm 0.9$ & 1.3 & 1.8 & 0.5 \\
\hline Female & $46.7 \pm 1.4$ & $60.2 \pm 1.3$ & $13.5 \pm 0.9$ & 1.5 & 1.9 & 0.4 \\
\hline \multicolumn{7}{|l|}{ Age (years) } \\
\hline $30-39$ & $8.3 \pm 2.3$ & $11.6 \pm 2.7$ & $3.3 \pm 1.6$ & 0.0 & 0.1 & 0.0 \\
\hline $40-49$ & $20.2 \pm 2.2$ & $30.9 \pm 2.8$ & $10.7 \pm 1.8$ & 0.2 & 0.3 & 0.1 \\
\hline $50-59$ & $29.1 \pm 2.0$ & $41.2 \pm 2.1$ & $12.2 \pm 1.3$ & 0.6 & 0.8 & 0.2 \\
\hline $60-69$ & $52.4 \pm 1.7$ & $66.6 \pm 1.6$ & $14.2 \pm 1.2$ & 1.0 & 1.2 & 0.3 \\
\hline $70+$ & $53.6 \pm 1.7$ & $70.9 \pm 1.5$ & $17.3 \pm 1.2$ & 1.0 & 1.3 & 0.3 \\
\hline \multicolumn{7}{|l|}{ Area of residence } \\
\hline Urban area & $38.2 \pm 1.2$ & $51.2 \pm 1.2$ & $13.0 \pm 0.7$ & 2.2 & 2.9 & 0.7 \\
\hline Rural area & $39.9 \pm 2.3$ & $54.0 \pm 2.5$ & $14.1 \pm 1.4$ & 0.6 & 0.8 & 0.2 \\
\hline \multicolumn{7}{|l|}{ Income quartiles } \\
\hline Highest & $40.5 \pm 2.0$ & $54.8 \pm 2.1$ & $14.3 \pm 1.4$ & 0.7 & 1.0 & 0.3 \\
\hline Upper middle & $37.9 \pm 1.9$ & $50.0 \pm 2.0$ & $12.1 \pm 1.2$ & 0.7 & 0.9 & 0.2 \\
\hline Lower middle & $36.4 \pm 1.9$ & $48.9 \pm 2.1$ & $12.5 \pm 1.2$ & 0.7 & 0.9 & 0.2 \\
\hline Lowest & $39.2 \pm 1.8$ & $53.3 \pm 1.9$ & $14.1 \pm 1.3$ & 0.7 & 1.0 & 0.3 \\
\hline \multicolumn{7}{|l|}{ Education levels } \\
\hline Primary & $46.7 \pm 1.4$ & $62.4 \pm 1.4$ & $15.8 \pm 1.0$ & 1.3 & 1.7 & 0.4 \\
\hline Middle & $41.1 \pm 2.4$ & $54.2 \pm 2.6$ & $13.0 \pm 1.6$ & 0.4 & 0.5 & 0.1 \\
\hline High & $36.5 \pm 1.9$ & $48.4 \pm 2.0$ & $12.0 \pm 1.2$ & 0.7 & 1.0 & 0.2 \\
\hline University/college & $24.7 \pm 2.0$ & $35.0 \pm 2.3$ & $10.3 \pm 1.4$ & 0.4 & 0.5 & 0.2 \\
\hline
\end{tabular}

Data are presented as mean \pm SE

KSH Korean Society of Hypertension

2017 ACC/AHA hypertension guidelines lowered the threshold for hypertension from $140 / 90 \mathrm{mmHg}$ to 130 / $80 \mathrm{mmHg}$ [13]. A study by Muntner et al. estimated the potential impact of the guidelines changes in U.S. adults, and expected a substantial increase in the prevalence of hypertension (from 31.9 to $45.6 \%$ ) [6].

However, the two guidelines are in a line that they both recommend intensive BP control $[9,10,13]$. The study by Muntner et al. estimated that the proportion of U.S. adults recommended to receive medical treatment would increase by $1.9 \%$ (from 34.3 to $36.2 \%$ ) [6]. As shown in this study, the number of Korean adults who meet the criteria for medical treatment increased remarkably (from 32.5 to $37.8 \%$ ). In a previous study, we showed that $35.3 \%$ of Korean adults would be recommended to receive antihypertensive medication when the 2017 ACC/AHA guidelines were directly applied the Korean population. Although the $2018 \mathrm{KSH}$ guidelines maintained the criteria for hypertension the adoption of more intensive BP control was consistent with the 2017 ACC/AHA guidelines. As a result, antihypertensive medical treatment is recommended for a significant proportion of Korean adults who are classified as having prehypertension.

The changes are also reflected in the decrease in the control rate. The target $\mathrm{BP}$ for uncomplicated general hypertensive adults was maintained at $<140 / 90 \mathrm{mmHg}$. However, as shown in Table 1, the target goal had been lowered for various subgroups compared with the 2013 version. For example, the $2013 \mathrm{KSH}$ recommended target systolic BP to be approximately 140 to $150 \mathrm{mmHg}$. In contrast, the $2018 \mathrm{KSH}$ guidelines stated that the effect of drug therapy against hypertension is clear irrespective of age, and recommended a target BP $<140 / 90$ $\mathrm{mmHg}$ in elderly hypertensive patients. In addition, the BP target goal for patients with complicated diabetes, high-risk profile, and cardiovascular disease had been lowered to $<130 / 80 \mathrm{mmHg}$. More intensive BP control would be necessary for those individuals to achieve the new BP goals.

The transitions are based on recent trial results. The SPRINT trial enrolled patients with systolic BP $\geq 130$ $\mathrm{mmHg}$ and a history of coronary artery disease, peripheral 
vascular disease, aortic disease, heart failure or left ventricular hypertrophy. The intensive strategy of lowering systolic BP $<120 \mathrm{mmHg}$ resulted in significantly lower rates of fatal and non-fatal major cardiovascular events compared to the conventional strategy of systolic BP $<140 \mathrm{mmHg}$ [4]. Meta-analyses also indicated that systolic BP $<130 \mathrm{mmHg}$ reduces major cardiovascular outcomes including stroke, coronary events, heart failure, and cardiovascular mortality compared with $>130 \mathrm{mmHg}$ [14-16]. The move toward intensive BP control is also similar in the U.S. and in Europe [5, 17]. Previous studies have shown hypertension awareness, treatment, and control rates increased remarkably until 2007, but showed a plateau thereafter $[12,18]$. The present study also suggests that there is room for improvement in BP control among Korean adults with hypertension.

One interesting finding in the present study is the relatively high-risk profile of the "elevated BP" group (systolic BP of 120-129 $\mathrm{mmHg}$ and diastolic BP $<80$ $\mathrm{mmHg}$ ). In the study by Muntner et al., which analyzed the U.S. population, the level of risk in this group was between those of the "normal" $(<120 / 80 \mathrm{mmHg})$ and "stage 1 hypertension" (130-139/80-89 mmHg) groups [6]. In the present study, their expected 10-year risk was higher than that of prehypertension (130-139/80-89 $\mathrm{mmHg}$ ), and comparable to that of grade 1 hypertension (140-159/90-99 mmHg). The key factor was age. The mean age of this group was even older than the age of those with grade 1 or 2 hypertension. This is consistent with the observations that pulse pressure (systolic BP minus diastolic BP) increases with age, and that increased pulse pressure is associated with higher risk of future cardiovascular events $[19,20]$. Subjects in this group are currently not candidates for antihypertensive treatment. The possibility of masked hypertension needs to be ruled out [21]. In addition, primary prevention such as lifestyle modification and cholesterol lowering should be considered for this group.

The major limitation of the present study originates from the data source. KNHANES is a nationally representative database that enrolls approximately 10,000 subjects living in Korea who were chosen by a complex stratified survey method. The use of KNHANES is the best way to estimate the impact in terms of the general Korean population. However, BP was measured during a single visit and a mercury sphygmomanometer was used by trained nurses. Recent evidence suggests unattended office BP measurement, ambulatory BP monitoring, and home BP monitoring may provide better estimates compared with conventional BP measurements [22-24]. In addition, while the presence of subclinical organ damages is used as one of the criteria for antihypertensive medical treatment in the $2018 \mathrm{KSH}$ guideline, they were not available from the database.

\section{Conclusions}

The present study revealed that the $2018 \mathrm{KSH}$ guidelines for hypertension compared to the 2013 version, recommend more intensive BP control in the Korean population. We found that would be a remarkable increase in the number of adults who are recommended to receive medical treatment, and a decline in the hypertension control rate. This study suggests that there is a large scope for improvement in BP control in Korean adults.

\section{Supplementary information}

Supplementary information accompanies this paper at https://doi.org/10. 1186/s40885-020-0137-5.

Additional file 1: Table S1. Prevalence of hypertension in Korea (2013-2015)

Additional file 2: Table S2. Hypertension control rate according to specific clinical conditions.

Abbreviations

ACC/AHA: American College of Cardiology/American Heart Association; BP: Blood pressure; KNHANES: Korea National Health and Nutrition Examination Survey; KSH: Korean Society of Hypertension

\section{Acknowledgements}

We thank Ms. Moon Ju Kim for performing data collection and statistical analyses.

\section{Authors' contribution}

JK and SH Kang designed the study. JK and SH Kim performed statistical analysis. SK and SH Kang wrote the manuscript with support from $\mathrm{CHY}, \mathrm{HYL}$ and KIK. TJY, IHC, and CHK critically reviewed the manuscript. All authors read and approved the final manuscript.

\section{Funding}

The research was supported by the funding of Korean Society of Hypertension (2018) (grant number KSH-R-2018-01).

\section{Availability of data and materials}

The data that support the findings of this study are available from the website (http://knhanes.cdc.go.kr). But restrictions apply to the availability of these data, which were used under license for the current study, and so are not publicly available.

\section{Ethics approval and consent to participate}

This study was exempt from review and the mandate for obtaining informed consent was waived by the Seoul National University Bundang Hospital Institutional Review Board (I-2019-208).

\section{Consent for publication}

Not applicable.

\section{Competing interests}

The authors declare that they have no competing interests.

\section{Author details}

${ }^{1}$ Cardiovascular Center, Department of Internal Medicine, Seoul National University Bundang Hospital, 82, Gumi-Ro 173 Beon-Gil, Bundang-Gu, Seongnam-Si, Gyeonggi-Do 13620, South Korea. ${ }^{2}$ Department of Internal Medicine, Seoul National University, Seoul, South Korea. ${ }^{3}$ Cardiovascular Center, Seoul National University Hospital, Seoul, South Korea. 
Received: 14 September 2019 Accepted: 12 January 2020

Published online: 01 February 2020

\section{References}

1. Forouzanfar MH, Liu P, Roth GA, Ng M, Biryukov S, Marczak L, Alexander L, Estep K, Hassen Abate K, Akinyemiju TF, et al. Global burden of hypertension and systolic blood pressure of at least 110 to $115 \mathrm{~mm} \mathrm{hg}$, 1990-2015. JAMA. 2017;317(2):165-82.

2. Danaei G, Finucane MM, Lin JK, Singh GM, Paciorek CJ, Cowan MJ, Farzadfar F, Stevens GA, Lim SS, Riley LM, et al. National, regional, and global trends in systolic blood pressure since 1980: Systematic analysis of health examination surveys and epidemiological studies with 786 country-years and 5.4 million participants. Lancet. 2011:377(9765):568-77.

3. Lewington S, Clarke R, Qizilbash N, Peto R, Collins R, Prospective Studies C. Age-specific relevance of usual blood pressure to vascular mortality: a metaanalysis of individual data for one million adults in 61 prospective studies. Lancet. 2002;360(9349):1903-13.

4. Group SR, Wright JT Jr, Williamson JD, Whelton PK, Snyder JK, Sink KM Rocco MV, Reboussin DM, Rahman M, Oparil S, et al. A randomized trial of intensive versus standard blood-pressure control. N Engl J Med. 2015; 373(22):2103-16.

5. Whelton PK, Carey RM, Aronow WS, Casey DE Jr, Collins KJ, Dennison Himmelfarb C, DePalma SM, Gidding S, Jamerson KA, Jones DW, et al. 2017 ACC/AHA/AAPA/ABC/ACPM/AGS/APhA/ASH/ASPC/NMA/PCNA guideline for the prevention, detection, evaluation, and Management of High Blood Pressure in adults: a report of the American College of Cardiology/American Heart Association task force on clinical practice guidelines. Hypertension. 2018;71(6):e13-e115.

6. Muntner P, Carey RM, Gidding S, Jones DW, Taler SJ, Wright JT Jr, Whelton PK. Potential U.S. Population Impact of the 2017 ACC/AHA high blood pressure guideline. J Am Coll Cardiol. 2018;71(2):109-18.

7. Lee JH, Kim SH, Kang SH, Cho JH, Cho Y, Oh IY, Yoon CH, Lee HY, Youn TJ,

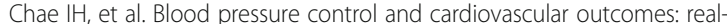
world implications of the 2017 ACC/AHA hypertension guideline. Sci Rep. 2018:8(1):13155

8. Kim HC, Ihm SH, Kim GH, Kim JH, Kim Kl, Lee HY, Lee JH, Park JM, Park S, Pyun WB, et al. 2018 Korean Society of Hypertension guidelines for the management of hypertension: part I-epidemiology of hypertension. Clin Hypertens. 2019;25:16

9. Lee HY, Shin J, Kim GH, Park S, Ihm SH, Kim HC, Kim Kl, Kim JH, Lee JH, Park $J M$, et al. 2018 Korean Society of Hypertension Guidelines for the management of hypertension: part II-diagnosis and treatment of hypertension. Clin Hypertens. 2019;25:20.

10. Kim Kl, Ihm SH, Kim GH, Kim HC, Kim JH, Lee HY, Lee JH, Park JM, Park S, Pyun WB, et al. 2018 Korean society of hypertension guidelines for the management of hypertension: part III-hypertension in special situations. Clin Hypertens. 2019;25:19.

11. Kweon S, Kim Y, Jang MJ, Kim Y, Kim K, Choi S, Chun C, Khang YH, Oh K Data resource profile: the Korea National Health and nutrition examination survey (KNHANES). Int J Epidemiol. 2014;43(1):69-77.

12. Kang SH, Kim SH, Cho JH, Yoon CH, Hwang SS, Lee HY, Youn TJ, Chae $\mathrm{H}$, Kim CH. Prevalence, awareness, treatment, and control of hypertension in Korea. Sci Rep. 2019;9(1):10970.

13. Reboussin DM, Allen NB, Griswold ME, Guallar E, Hong Y, Lackland DT, Miller EPR 3rd, Polonsky T, Thompson-Paul AM, Vupputuri S. Systematic Review for the 2017 ACC/AHA/AAPA/ABC/ACPM/AGS/APhA/ASH/ASPC/NMA/PCNA guideline for the prevention, detection, evaluation, and Management of High Blood Pressure in adults: a report of the American College of Cardiology/American Heart Association task force on clinical practice guidelines. Hypertension. 2018;71(6):e116-35.

14. Reboussin DM, Allen NB, Griswold ME, Guallar E, Hong Y, Lackland DT, Miller EPR 3rd, Polonsky T, Thompson-Paul AM, Vupputuri S. Systematic Review for the 2017 ACC/AHA/AAPA/ABC/ACPM/AGS/APhA/ASH/ASPC/NMA/PCNA guideline for the prevention, detection, evaluation, and Management of High Blood Pressure in adults: a report of the American College of Cardiology/American Heart Association task force on clinical practice guidelines. Circulation. 2018;138(17):e595-616.

15. Bangalore S, Toklu B, Gianos E, Schwartzbard A, Weintraub H, Ogedegbe G, Messerli FH. Optimal systolic blood pressure target after SPRINT: insights from a network meta-analysis of randomized trials. Am J Med. 2017;130(6): 707-19 e708.
16. Thomopoulos C, Parati G, Zanchetti A. Effects of blood pressure lowering on outcome incidence in hypertension: 7. Effects of more vs. less intensive blood pressure lowering and different achieved blood pressure levels updated overview and meta-analyses of randomized trials. J Hypertens. 2016:34(4):613-22

17. Williams B, Mancia G, Spiering W, Agabiti Rosei E, Azizi M, Burnier M, Clement DL, Coca A, de Simone G, Dominiczak A, et al. 2018 ESC/ESH guidelines for the management of arterial hypertension. Eur Heart J. 2018; 39(33):3021-104

18. Korean Society $H$, Hypertension epidemiology research working G, Kim HC, Cho MC. Korea hypertension fact sheet 2018. Clin Hypertens. 2018;24:13.

19. Choi YJ, Kim SH, Kang SH, Yoon CH, Lee HY, Youn TJ, Chae $\mathrm{H}_{1}$ Kim CH. Reconsidering the cut-off diastolic blood pressure for predicting cardiovascular events: a nationwide population-based study from Korea. Eur Heart J. 2019:40(9):724-31.

20. Franklin SS, Larson MG, Khan SA, Wong ND, Leip EP, Kannel WB, Levy D. Does the relation of blood pressure to coronary heart disease risk change with aging? The Framingham Heart Study. Circulation. 2001;103(9):1245-9.

21. Banegas JR, Ruilope LM, de la Sierra A, Vinyoles E, Gorostidi M, de la Cruz JJ, Ruiz-Hurtado G, Segura J, Rodriguez-Artalejo F, Williams B. Relationship between clinic and ambulatory blood-pressure measurements and mortality. N Engl J Med. 2018;378(16):1509-20.

22. Myers MG, Godwin M, Dawes M, Kiss A, Tobe SW, Kaczorowski J. Measurement of blood pressure in the office: recognizing the problem and proposing the solution. Hypertension. 2010;55(2):195-200.

23. Parati G, Stergiou G, O'Brien E, Asmar R, Beilin L, Bilo G, Clement D, de la Sierra A, de Leeuw P, Dolan E, et al. European Society of Hypertension practice guidelines for ambulatory blood pressure monitoring. J Hypertens. 2014;32(7):1359-66.

24. O'Brien E, Parati G, Stergiou G, Asmar R, Beilin L, Bilo G, Clement D, de la Sierra A, de Leeuw P, Dolan E, et al. European Society of Hypertension position paper on ambulatory blood pressure monitoring. J Hypertens. 2013:31(9):1731-68.

\section{Publisher's Note}

Springer Nature remains neutral with regard to jurisdictional claims in published maps and institutional affiliations.
Ready to submit your research? Choose BMC and benefit from:

- fast, convenient online submission

- thorough peer review by experienced researchers in your field

- rapid publication on acceptance

- support for research data, including large and complex data types

- gold Open Access which fosters wider collaboration and increased citations

- maximum visibility for your research: over $100 \mathrm{M}$ website views per year

At BMC, research is always in progress.

Learn more biomedcentral.com/submissions 